\title{
Multilevel Design for Smart Communities - The Case of Building a Local Online Neighborhood Social Community
}

\author{
Christian Grotherr \\ University of Hamburg \\ christian.grotherr@uni- \\ hamburg.de
}

\author{
Pascal Vogel \\ University of Hamburg \\ pascal.vogel@uni-hamburg.de
}

\author{
Martin Semmann \\ University of Hamburg \\ martin.semmann@uni- \\ hamburg.de
}

\begin{abstract}
Smart cities and communities aim for social wellbeing. Mobilizing and integrating various institutions, actors, and resources are crucial when building and instantiating smart community initiatives. The design of such an arrangement is a complex phenomenon, difficult to conduct systematically and to observe empirically. We address this challenge by applying a multilevel design framework for service systems to an ongoing design science research project. The research project pursues the goal of building a neighborhood community as an instantiation of smart communities by activating and leveraging local institutions, actors, and resources on an IT-enabled engagement platform. We demonstrate how this multilevel perspective informs the design process for building smart communities. Based on micro-level observations, the interdependence of engagement-stimulating mechanisms related to the platform's design at the meso-level, and design implications for the institutional arrangement at the macro-level are emphasized as inseparable design activities for mobilizing and integrating actors and resources.
\end{abstract}

\section{Introduction}

Developing smart cities, which are driven by new technology to enhance citizen well-being, has become a major priority for urban and rural governments [1]. Local governments invest heavily in exploring new ways to become smarter, connected, and more sustainable [2]. Although the broader concept of smart cities has been investigated in previous research [3], current research seeks to dig deeper into the design of smart communities, which are connected to improve well-being [4]. Thus, we focus on neighborhoods as instantiations of smart communities in smart cities. Social exclusion is an increased risk which affects the aging population, especially in growing metropolitan regions, and leads to increasing anonymity in residential neighborhoods [5]. This cycle of growing anonymity is overcome by initiatives that integrate infrastructure, technical and human resources, into social neighborhood communities [6]. In this context, cities have begun to address the challenge of an aging society by implementing neighborhood services, which are facilitated by information technology [7]. Technological advancements can help increase social inclusion and improve accessibility to urban environments. The positive effect on social well-being of integrating various actors with information technology has been shown in previous studies [7, 8].

Although extant research recognizes that building smart communities is a multidimensional effort [9], little is known about how to utilize this concept. Designing smart communities is even more abstract, and designing collaboration between actors challenging [10]. From a sociotechnical perspective, mobilizing and integrating various actors requires more than technological advancements [11]. Individuals are shaped by technological design, and at the group level by social control, norms, and values [12, 13]. This results in integration activities of technological advancements, institutions, and infrastructures with human interests. Diverse interests and changing environments lead to uncertainties when building smart communities. In turn, building smart communities should not be a matter of coincidence, but systematically coordinated and supported by institutional arrangements.

As knowledge of how to manage and systematically conduct design actions for building smart communities with the use of technology is scarce [14], new approaches are required which adapt to varying circumstances. This leads us to the following research question: How can design activities be conducted systematically to build smart communities?

To investigate this research question in detail, we analyzed a social community building project that aims to improve peer-support services and access to resources of local service providers. By applying 
mechanisms of local neighborhood communities, we aim to capture insights into building smart communities by engaging multiple actors, ranging from institutions to individual actors (citizens). Specifically, we build on an IT-enabled neighborhood service platform, which facilitates mobilization and integration of resources, and aims to ensure a high quality of life for citizens.

The aim of the ongoing research project is to ramp up and build conditions for an emergent smart community. Especially among an aging population [5], individual needs must be captured, to facilitate a rethinking of mental models toward an open, networked, and informed smart community. Based on this research project, we enhance our understanding of building smart communities in smart cities by adopting a service systems perspective, with an emphasis on peer-support services, facilitated by technology use. We adapt a multilevel perspective for service systems design that helps to operationalize and manage design activities to build a smart community. We conclude that smart cities, smartness, and related components are not only multidimensional [9] but also relate to a multilevel perspective. The proposed multilevel model helps to manage complexity on (1) multiple levels and (2) with dynamics in changing environments, by pointing out the path to social well-being with corresponding design activities and elements. This means engaging citizens at the micro-level, facilitated by intermediaries, such as engagement platforms at the meso-level, which leads to value co-creation at the macro-level. This perspective extends beyond the adaption of information technology by integrating actors and institutions as designable elements and results in a systematic approach to build smart communities. We further derive recommendations for engagement-facilitating mechanisms, and provide a novel perspective on social community building.

The remainder of this paper is structured as follows: Section 2 summarizes related work on smart and neighborhood communities, and service systems conceptualizations. Section 3 describes the methodology and the research project. Section 4 provides an in-depth research project description according to the multilevel framework. Section 5 discuss the evaluation results, followed by implications in section 6. Finally, section 7 summarizes the research results and identify future research work.

\section{Theoretical background}

\subsection{Smart and neighborhood communities}

The technological, institutional, and human dimensions of smart cities are frequently discussed [9].
Institutional aspects relate to regulations, governance, and policies, while social dimensions aim to respond to human interests, such as health or education issues [15]. Technology components range from smart infrastructure to the application of information technology to integrate citizens within an engagement process via engagement platforms $[10,16]$. Previous research on citizen engagement aimed at creating participatory innovation platforms, on which the democratic culture is reflected in shaping policy decisions and open innovation approaches [17, 18]. This reflects the integrated perspective of technology as a key enabler for smart cities to engage citizens in the decision process with the aim of increasing environmental sustainability [19].

Recent research extended citizen engagement to the concept of smart communities, in which the community members and infrastructures are connected via technology to improve well-being $[15,20]$. Smart communities can be defined as "a community broadly ranging from a small neighborhood to a nation-wide community of common or shared interest, whose members, organizations and governing institutions are working in partnership to use IT to transform their circumstances in significant ways" [9, p. 286]. In this sense, smart communities connect local governments and institutions, and inhabitants to impact life and work in the local region positively [9].

Engaging citizens via technology to increase geographic and social proximity is key to the success of smart communities [21]. A strategy for engaging in local communities is to build on online social networks (OSNs) [22, 23]. Online social networks provide the opportunity to connect organizations, and citizens among themselves. Thus, bridging access to local actors and resources by using online social network technology, such as engagement platforms, raises the opportunity to integrate offline and online activities into one unified instance [16]. However, although online social networks are not limited to regional boundaries, the networks do not address the specific needs of local communities [24]. Establishing neighborhood communities is a challenging process, due to the focus on localness. Stricter requirements regarding trust and privacy among participants, in conjunction with a limited number of actors, may hamper the formation of a critical mass of neighbors.

\subsection{Service systems and engineering}

Service systems have emerged as a service research priority, are defined as "complex sociotechnical systems that enable value co-creation" [25, p. 73], and focus on actors, resources, and institutional arrangements for value co-creation [26]. Value is 
created through an interactive process of engaging actors, and resource mobilization is key for service systems interaction [27]. Adapting information technology, such as engagement platforms, emerged as a phenomenon that facilitates communication and coordination of relationships between actors and the creation of new service systems [28, 29]. Finding the right configuration of actors, resources, and information technology is a key activity for interactive value co-creation [30]. The systematic design is addressed by the service systems engineering discipline [25], which focuses on the design of (1) service architecture, (2) service systems interaction, and (3) resource mobilization with models, methods, and artifacts [25].

From a service systems perspective, smart communities are sociotechnical systems [31] that comprise various actors, ranging from the government, organizations, and institutions to individual citizens, as well as their resources, such as local infrastructures. The shift of the actors' role from passive consumers to active contributors to co-create value in service research [26, 30] is reflected in smart community initiatives, which aim to transform the role of the citizen as a passive inhabitant into an active contributor to policy decision making or data-generation, or as an actor in a local, connected community, by using information technologies [32]. Despite thorough conceptualizations of smart cities and smart communities [15, 32], knowledge of how to operationalize value creation and related design activities is scarce [33]. Solely addressing an abstract level of smart communities is not sufficient, as this perspective lacks consideration of actor engagement on an individual level. Therefore, we apply a multilevel design framework as part of the service systems engineering which enhances our understanding of design decisions, and the resulting effects on actor engagement [34]. We demonstrate the applicability of the multilevel framework by applying it to our research project for building a neighborhood community as an instantiation of smart communities.

\section{Methodology}

Realizing value in smart communities is difficult to plan and observe, due to the time gap between the initial design and the realized value for the smart community initiative. Building on the microfoundation movement, and actor engagement as a micro-foundation for value co-creation [27, 35], drilling down to a granular and empirical observable level bridges the gap between the abstract concept of value co-creation at the macro-level with empirically observable actor engagement at the micro-level. We build on a multilevel conceptualization of service systems design to link the abstract goal of building smart communities, to achieve social well-being with manageable and observable design activities (see Figure 1). The framework provides an analytical perspective, and helps to address the dynamics in smart community building and evolution. The framework increases understanding of value co-creation outcomes by analyzing the effects of the design decision at each level, and enables a systematic derivation of design knowledge for non-deterministically plannable actor engagement [36].



\section{Figure 1. Multilevel design framework for service systems (based on [34])}

The multilevel framework is conceptualized by (1) a multilevel perspective with macro-, meso-, and micro-levels and (2) two iterative design processes [34]. The three-level model entails a macro-level institutional setup, which incorporates the value proposition and a configurations of actors and resources. The meso-level mediates with sociotechnical components that facilitate engagement. The micro-level is represented by actor engagement, which "is conceptualized both the disposition to engage and the activity of engaging in an interactive process of resource integration within the institutional context provided by a service ecosystem" [27, p. 3008]. Actor engagement can be empirically observed by temporal, informational and relational engagement properties [37]. Actor's interaction and willingness to engage is shaped by the social context and platform's design [36]. This is in line with the sociotechnical perspective, which defines the technology and social behavior of individuals as an inseparable instance of analysis [11]. Finally, actor engagement activities are transitioned back to the macro-level as an aggregated unit of value co-creation [27].

Due to the contextual nature of value co-creation and the simultaneous interaction of the actors, a dynamic perspective is required. Therefore, the design process is conceptualized as a sequence of design activities at all levels. The designable components are linked within two intertwined design cycles: (1) 
institutional design and (2) engagement design. We distinguish with the multilevel perspective between the individual encounter design of engagement platforms and supporting interventions (engagement design), and the design of the institutional setup related to the configuration of the engaged actors and resources, and the guiding value proposition (institutional design). This requires different methods and measurements. The engagement design relates components to engagement-facilitating mechanisms, such as engagement platforms [34]. User experience with a sociotechnical perspective is crucial for the design of the artifact, which can be captured through useroriented methods, such as design thinking, and lowfidelity prototypes [38]. Further, piloting of engagement platforms is crucial to achieve progress in building smart communities. This approach provides tangible results, evaluates the impact of smart community initiatives, and keeps motivation high for further engagement [39]. Based on the evaluation results, indications of the impact and further actions can be derived for engagement or institutional design.

To derive design implications for smart communities, we apply this framework by conducting a case study based on Yin's work [40] within one of our design science research (DSR) projects in the context of smart communities (see Table 1). As part of this DSR project, we build an engagement platform within a neighborhood (online) communities as described in the following section.

Table 1. Case research project for building smart communities

Service system: Neighborhood community comprising of several actors and guided by value propositions

Actors: institutions, neighbors, service providers

Resources: infrastructures and services of actors

Value proposition: Engaging actors and resources in a local and social neighborhood community for improving social well-being

Applied principle: Local (online) neighborhood social networks

Tool support: Engagement platform

Research approach: Design science research

Data collection and analysis: Thinking aloud, interviews, focus groups, evaluation diaries

\section{Case description: research project for building smart communities in neighborhoods}

In the following, we describe and analyze our DSR project (see Table 1) and the multilevel design framework (see Figure 1). We first describe within the institutional design cycle our research context, and propose the guiding value proposition, which is based on challenges, as well as opportunities, for smart communities (section 4.1). We build a design hypothesis to improve the social well-being in smart communities and intervene in the natural environment of two neighborhood communities by proposing and building an engagement platform as an intermediary for collaborative interactions in a neighborhood community as part of the engagement design (section 4.2). We intervene in a neighborhood environment by using a prototype, and reflect the design decisions, leading to implications for further design activities for engagement and institutional design (section 5).

\subsection{Overall research context and objectives}

Smart cities shift the focus from the technical equipment of infrastructures to building social systems and evolving ecosystems [14, 41]. Building on the smart community concept, local governments have recognized the need to facilitate social capital and the formation of smart communities. In 2016, the public health authority of a large German metropolitan region funded this smart community initiative to respond to the social and healthcare needs of an aging society in urban environments [6]. To ensure relevance and applicability in practice, we have been carrying out a DSR project for three years in a naturalistic environment. We engaged in two urban neighborhoods with 1200 and 4800 inhabitants in a large metropolitan area in Germany. Due to our piloting approach [42], these two quarters provide a rich set of intervention and evaluation activities.

As the first step, we identify the current issues and opportunities for smart communities as part of the institutional design. Building on a literature review on neighborhood social networks [43], we extended our insights by conducting two workshops. As engaging the potential users is crucial in smart city projects [44], the workshops were conducted with 3 representatives of a neighborhood management service (quarter 1) and with 12 citizens (quarter 2).

Despite the presence of increased anonymity issues in metropolitan regions, participants confirmed a lack of transparency concerning services offered by local organizations, as well as opportunities to provide services by neighbors for neighbors along the lines of peer-support services [45]. Limited access to online platforms leads to limited access to services of local service providers and institutions, such as the police or church. Consequently, the primary goal of the project is to build on mechanisms that support integrating services and volunteering, which increase citizens' 
quality of life and well-being [6]. This entails connecting younger citizens and the elderly population with each other, as well as with local infrastructures, to increase social inclusiveness, accessibility, and service proximity [46]. This leads to the following value proposition, which guides further design activities: "Engaging actors and resources in a local and social neighborhood community to improve social wellbeing".

\subsection{Applied mechanism and artifact for intervention in the actor's environment}

Our research is motivated by the aim of increasing the social inclusion and accessibility of local actors and infrastructures. This faces the challenge of an aging society [5]. Therefore, we applied OSNs and neighborhood social network mechanisms. Prominent examples of online social networks, such as Facebook, serve as mechanisms for building local social networks [24]. A specific type of local social networks is neighborhood social networks, which aim to enhance social support and increase self-efficacy [47]. However, knowledge of how to design local neighborhood social networks by using online social network technology is scarce [43]. In addition, (online) social networks and existing neighborhood services do not consider the needs of the elderly population [48, 49].

Encouraging technologies as intermediaries unlocks new solutions from which inhabitants can benefit. The goal is to utilize the community's ability to provide peer-support services, local service provider offerings, and institutions as facilitators with technologies, such as engagement platforms. This platform thinking is gaining more importance since the platform economy emerged as a promising opportunity to adapt collective intelligence and resources [45]. Engagement platforms are defined as "physical or virtual touch points designed to provide structural support for the exchange and integration of resources, and thereby co-creation of value between actors in a service system" [50, p. 596]. Thus, engagement platforms provide a promising design hypothesis for engaging local neighbor actors in a social community.

As value co-creation in smart communities depends on individual contextual factors, an empirical investigation into an actor's natural environment is essential to observe the effects of design decisions in certain contexts [51]. This reflects the transition from institutional design to engagement design. Actors' disposition to engage is difficult to determine in advance, and is related to multiple possible design decisions [52]. Thus, building sociotechnical artifacts requires human-centered approaches to gain insights into human behavior. For instantiating the engagement platform, we first used human-centered design approaches, such as design thinking, personas, and user stories, to identify a suitable solution design [53]. Then, we developed the engagement platform in several propose, build, intervene, and reflect iterations, starting with low-fidelity, paper-based prototypes, leading to a technical instantiation. In general, the platform implements technical features to stimulate peer-support services in the neighborhood community. This is done with features, which enable inhabitants to request and offer assistance, for example, for replacing incandescent lights or offering a service to conduct daily shopping. Further functionality to stimulate engagement is implemented, such as detailed profile information to discover other peers, contribution functions, such as likes and comments, and notifications to inform users about updates [54].

Service providers and local organizations are integrated on the engagement platform to make offline services visible and accessible to the community members. Therefore, the engagement platform implements features to create an organization profile with relevant information, such as opening hours, and promote offerings in the neighborhood.

As engaging actors are limited to the design of the platform, the underlying constraints must be gathered, and analyzed regarding the effects on individual behavior, which, in turn, leads to adjustments of design decisions. Therefore, we conducted naturalistic evaluation activities according to Venable, et al.'s work [55]. First, we conducted a user experience workshop with 20 potential users. Users aged between 53 and 85 years were selected to examine the needs of elderly users. Second, we conducted a field test with 35 inhabitants over a period of three months. Participants were granted access to the mobile application. Data were collected via evaluation diaries [56], as well as via personal support. As the artifact is placed within the naturalistic environment, we apply a sociotechnical perspective with an "ensemble view" to derive insights into the use and social effect of the artifact [57].

\section{Findings and insights}

Table 2 provides a brief reflection based on the observed micro-level results and implications for the sociotechnical components as part of the engagement design at the meso-level, and the institutional setup as part of the institutional design at the macro-level.

Trust and privacy concerns are emphasized during the evaluation. Fake accounts and information sharing outside the platform are issues, which must be addressed during the design process (Table 2, \#1). 


\begin{tabular}{|c|c|c|c|}
\hline \# & $\begin{array}{l}\text { Micro-level } \\
\text { results }\end{array}$ & $\begin{array}{l}\text { Meso-level } \\
\text { implication }\end{array}$ & $\begin{array}{l}\text { Macro-level } \\
\text { implication }\end{array}$ \\
\hline 1 & $\begin{array}{l}\text { Trust and } \\
\text { privacy } \\
\text { concerns }\end{array}$ & $\begin{array}{l}\text { Providing and } \\
\text { verifying real } \\
\text { user profiles } \\
\text { information }\end{array}$ & $\begin{array}{l}\text { Engaging } \\
\text { trust- } \\
\text { supporting } \\
\text { actors }\end{array}$ \\
\hline \multirow{2}{*}{2} & \multirow{2}{*}{$\begin{array}{l}\text { Lack of } \\
\text { access }\end{array}$} & $\begin{array}{l}\text { Establish } \\
\text { offline support } \\
\text { and training }\end{array}$ & $\begin{array}{l}\text { Mobilize } \\
\text { actors and } \\
\text { resources }\end{array}$ \\
\hline & & $\begin{array}{l}\text { Age-friendly } \\
\text { platform } \\
\text { design }\end{array}$ & \\
\hline \multirow[b]{2}{*}{3} & \multirow[b]{2}{*}{$\begin{array}{l}\text { Need } \\
\text { engagement } \\
\text { stimulation }\end{array}$} & $\begin{array}{l}\text { Provide initial } \\
\text { contributions }\end{array}$ & \\
\hline & & $\begin{array}{l}\text { Engage } \\
\text { neighborhood } \\
\text { community } \\
\text { management }\end{array}$ & $\begin{array}{l}\text { Employ } \\
\text { neighborhood } \\
\text { community } \\
\text { management }\end{array}$ \\
\hline \multirow[b]{2}{*}{4} & \multirow{2}{*}{$\begin{array}{l}\text { Facilitate } \\
\text { engagement } \\
\text { of various } \\
\text { actors }\end{array}$} & $\begin{array}{l}\text { Integrate local } \\
\text { institutions } \\
\text { and service } \\
\text { providers }\end{array}$ & $\begin{array}{l}\text { Mobilize and } \\
\text { commit } \\
\text { actors }\end{array}$ \\
\hline & & $\begin{array}{l}\text { Install spaces } \\
\text { and screens to } \\
\text { promote } \\
\text { exchange } \\
\text { between actors }\end{array}$ & \\
\hline
\end{tabular}

We decided to register users with their real names and addresses, and restricted access to the platform with a registration process to improve trust in the neighborhood community [58]. This requires a process to confirm user profiles, and institutions of trust, such as local churches or police stations, have to be mobilized and integrated, to mediate as non-profit organizations in verifying real names and addresses.

The evaluation results further indicate various necessary interventions to provide access to the platform for older actors in particular (Table 2, \#2). Young actors expect technical support via electronic channels, such as e-mail, but older actors chose to receive in-person support. For providing support structures, actors have to be mobilized to meet the inhabitants' expectations. This requires resources and responsibilities; specifically, we coordinate neighborhood community management to offer on-site support. In addition, some older users struggle when using the platform on mobile devices. To this end, we provide bi-weekly smartphone usage training to prepare older actors to use the mobile application. For future technology training support, public libraries may serve as anchor institutions to provide basic technology courses [59].
However, even if the research project aims to build an age-appropriate platform (see Table 2, \#2), the design and guiding value proposition may not deter younger and older actors. This is also reflected in previous studies, which indicates that older inhabitants prefer to live within the community instead of residential care [60]. The inclusion of the elderly in the neighborhood networks inevitably requires the entire community be connected, older and younger. Solely restricting and actively promoting age-appropriate functions, thus, would be a signal for forcing older communities exclusively, and would negate the integrative approach. Therefore, the inclusion of older people is the focus, and supported by features and services. However, the overall goal is to improve wellbeing in the overall urban space, and to eliminate boundaries between younger and older citizens.

Therefore, we enforce peer-support services on the platform. However, peer-support services may be restricted due to lack of engagement by actors (Table 2, \#3), as we also faced a causality dilemma: The actors' willingness to participate in peer-support services may be genuine, but without any open support requests, there is no opportunity to volunteer help. As previous research demonstrates [34], initial contributions and events populated by neighborhood management reduce engagement barriers. To facilitate interaction, neighborhood community managers are employed, to support inquiries between individual actors and local service providers.

Further, as previous research highlights, the role of institutional actors, such as public libraries, as facilitators in building smart communities is recognized [59]. Access to local service providers, institutions, and infrastructures is a prerequisite for facilitating actor engagement (Table 2, \#4). Key enablers are among others, churches, police stations, and non-profit organizations, which enhance trust within the neighborhood community. Thus, we link local service providers, neighborhood managers and institutions on the engagement platform to stimulate engagement via events, and create a marketplace for peer-support services. They organize leisure and health education events, as well as increase accessibility for older citizens by partnerships with health and elder care services. Additionally, to promote neighbor relationships outside the engagement platform, crossgenerational spaces and large outdoor touchscreens are available, which facilitate the exchange between the engaging actors. Health-promoting offerings in the neighborhood, such as Nordic walking, and other inhabitant-relevant information, such as cultural events or building sites are provided. Consequently, several dedicated actors and resources must be engaged to stimulate activity in the neighborhood community. 


\section{Discussion}

Our research contributes to the realm of building smart communities, as we investigate design activities on multiple levels. Decomposing smart community building on multiple levels, and applying iterative design cycles, captures dynamics in context and turns the process into manageable activities for the researcher and the practitioner. Second, we derive design implications based on the ongoing DSR project, which aims to build an online neighborhood community as a manifestation of smart communities.

We conclude that smart communities can be referred to as fluid organizational forms, which must be managed as such. The formation of smart communities is a complex process, as various actors simultaneously engage on a voluntary basis and try to satisfy their goals. These goals are guided by the actors' disposition to engage. This leads to possibly conflicting goals and values. Even if actors engage in collaboration activities, individual actions can be contrary to collective action, and thus, hinder joint value creation, ultimately leading to value deconstruction [61]. Therefore, the interests of individuals must be aligned with the interests of the smart community. In this sense, actors should not be treated as recipients of a designed artifact, but actively engaged in the design project, which requires humancentered methods [62].

As our results shows, applying a service system perspective is particularly useful to grasp the objectives of smart community building. Local (online) social neighborhoods as an instantiation of smart communities integrate technology, humans, institutions and local service providers, and physical components as resources. Previous research on smart cities focuses on technology [63] and governance [64], but we propose to apply an integrative, multilevel perspective, which enhances our understanding of the interrelations of sociotechnical components and engaging actors, ranging from individual engagement to institutional actors' engagement. This perspective bridges macrolevel goals with micro-level observations and explanations [65]. Especially, as information systems are multilevel [66], we explore how this perspective support analysis of sociotechnical artifacts and organizational and institutional boundaries, affecting the actors' engagement and technology use.

In particular, the multilevel framework helps to decompose a value proposition into manageable and measurable steps, and connect them. We propose a guiding value proposition of smart and connected communities for social well-being as a strategic improvement at the macro-level, which is based on the basic concept of collaborative and interactive value co- creation [26]. These objectives are reflected by neighborhood (online) social networks, and are incorporated by engagement platforms as facilitators to generate peer-support services at the meso-level. Intervening in the actor's environment helps to observe the effects of design decisions at the micro-level, which, in turn, must be reflected at the meso- and macro-levels. As the results indicate, the actors' engagement is limited due to the functions of the platform. At the same time, several engagementsupporting interventions, such as promotions and training, affect actors' willingness to engage, and have to be applied to the engagement platform. This is in line with the sociotechnical perspective, which describes technical elements and social practices as inseparable elements when analyzing and designing artifacts $[11,57]$.

However, designing sociotechnical artifacts is not solely related to the design of the system. Even if platforms design assumes to address the target group needs, the design implications are twofold. We propose that engaging individual actors requires engagementstimulating mechanisms, such as sociotechnical platforms and functions (e.g., communication and peersupport requests), as well as supporting institutions and organizations, which stimulate engagement and enhance perceived value expectation. The need for an age-friendly design of the smart community is not mainly fulfilled by the design of an age-appropriate platform, but by specific interventions, such as training, or incorporation of trust-building institutions, such as churches (see Table 2, \#2). These institutions should be mobilized and integrated, and reflect the (reconfiguration of the institutional setup of the actors and resources at the macro-level.

To sum up, to get smart and connected individual and institutional actors, the resources and infrastructures must be mobilized and integrated. By engaging service providers, local organizations, institutions, and non-profit organizations, we emphasize their role as intermediaries of values such as trust. This requires the engagement of multiple actors in the institutional design of smart communities. Therefore, creating the institutional setup with corresponding design elements, such as the guiding value proposition and the configuration of engaging actors and resources, is crucial for building the preconditions of successful actor engagement and value co-creation [34]. At the same time, refinements of the institutional setup are required to find the right configuration of actors and resources. These design activities facilitate resource mobilization, help to increase local smart community growth, and reduce, for example, the identified engagement barriers of individual actors at the micro-level [34]. Thus, the 
value proposition and the configuration of engaging actors and resources must be adapted, and evolve over time. However, these developments require a longterm effort to reinforce the new structures and increase public value. These continuous refinements and adjustments of the institutional setup require a longterm commitment of several actors, and to measure the achieved value. This, in turn, leads to transformation results for engaging individual and institutional actors.

However, there is no silver bullet to increase smartness. Various engaging actors, different infrastructures and institutional arrangements, as well as rapidly changing contexts, make it difficult to systematically plan and operationalize design initiatives [67]. One central requirement for building smart communities is the ability to react to these dynamics, and reconfigure actors, resources, institutions, and information technology. An explorative approach is required to understand the design decisions about the networked value co-creation of multiple engaging actors, and to understand how this community evolves over time. The proposed iterative design and validation cycles create a continuous process of change, which includes experiments and improvements, and leads to a deeper understanding of anticipated and unanticipated implications of the design decisions.

\section{Conclusion}

Smart communities have emerged as a priority for local governments and researchers. Building smart communities necessitates a focus on human behavior. The effects of design decisions and engaging actors on perceived trust and usefulness is central to an actor's willingness to engage, and must be analyzed and translated into implications for actions. However, little is known about how to systematically conduct design activities for building smart communities.

This paper contributes in two respects: It provides (1) a case discussion of how engagement platforms serve as a mediator of actors and resources with corresponding design implications based on an ongoing DSR project and (2) a multilevel perspective for analyzing and systematically deducing design implications. We provide two implications for practitioners and researchers. First, considering individual citizens when designing technologymediated engagement is crucial for building smart communities (engagement design). Second, institutions as facilitators and promoters play a role in initiating and scaling up smart communities (institutional design). Linking both design activities with an engagement platform as an intermediary is the key to scale and sustain actor engagement.
We draw on insights from an ongoing DSR project that aims to build a smart community. By applying local (online) social neighborhood mechanisms and engagement platforms, we seek to integrate physical resources, services of local organizations, and peersupport services within a local neighborhood context. This enables the exploration of the evolution of smart communities, and prompts implications for mobilizing and integrating resource.

Informed by a service systems perspective, smart communities as a system of engaging actors and resources are guided by the value proposition of social well-being. However, engagement may be restricted due to sociotechnical issues and the institutional setup, which lead to limited expectations for the value contribution. We emphasize the multilevel process that comprises several measuring and reflection stages. Thus, the ramping-up phase revealed the need for several interventions and engagement of institutions to set up the conditions for smart communities. We conclude that building smart communities entails the task of designing and refining sociotechnical components, as well as the institutional setup, to stimulate engagement of individual and institutional actors. Several actors, resources, infrastructures, and institutions should be integrated while considering institutional arrangements, trust, and privacy issues. However, knowledge of how to manage such a complex undertaking is scarce.

The applied multilevel perspective shed light on building smart communities, which helps decompose abstract design goals into manageable and observable design implications. The two intertwined design cycles seek to bridge the gap between designing sociotechnical components at the meso-level and integrating the engagement of supporting actors and institutions at the macro-level. From a managerial perspective, this framework offers an explanatory framework and prescriptive guidance to systematically plan and conduct design activities, and contribute to the management of smart cities and communities.

Future research should investigate the roles of institutional actors, such as universities, schools, and libraries, and measurements of the value achieved. Therefore, we plan to conduct a full public launch of the platform, combining several further qualitative evaluations and quantitative analysis of platform usage.

\section{Acknowledgements}

This research was funded by the German Federal Ministry for Education and Research (ExTEND, reference 02K14A170) and the European Regional Development Fund and the City of Hamburg (AGQua, reference Z|74012|2016|G500-02.10|10.009-03-EFRE). 


\section{References}

[1] E. Marlier, Europe 2020: towards a more social EU? (no. 69). Peter Lang, 2010.

[2] B. T.-R. Bill Finnerty "Hype Cycle for Smart City Technologies and Solutions," 2018.

[3] R. Jucevičius, I. Patašienè, and M. Patašius, "Digital dimension of smart city: critical analysis," Procedia-Social and Behavioral Sciences, vol. 156, 2014.

[4] M. Gurstein, "Smart cities vs. smart communities: empowering citizens not market economics," The Journal of Community Informatics, vol. 10, no. 3, 2014.

[5] L. Plouffe and A. Kalache, "Towards Global AgeFriendly Cities: Determining Urban Features that Promote Active Aging," International Journal of Urban Health, journal article vol. 87, no. 5, pp. 733-739, 2010.

[6] T. Buffel, C. Phillipson, and T. Scharf, "Ageing in urban environments: Developing 'age-friendly'cities," Critical Social Policy, vol. 32, no. 4, pp. 597-617, 2012.

[7] H. Hasan and H. Linger, "Enhancing the wellbeing of the elderly: Social use of digital technologies in aged care," Educational Gerontology, vol. 42, no. 11, pp. 749-757, 2016. [8] W. J. Chopik, "The Benefits of Social Technology Use Among Older Adults Are Mediated by Reduced Loneliness," Cyberpsychology, behavior and social networking, vol. 19, no. 9, pp. 551-556, 2016.

[9] T. Nam and T. A. Pardo, "Conceptualizing smart city with dimensions of technology, people, and institutions," in Proceedings of the 12 th annual international digital government research conference: digital government innovation in challenging times, 2011: ACM, pp. 282-291.

[10] P. Pierce and B. Andersson, "Challenges with smart cities initiatives-A municipal decision makers' perspective," 2017.

[11] W. J. Orlikowski and C. S. Iacono, "Research commentary: Desperately seeking "IT" in IT research - A call to theorizing the IT artifact," Information Systems Research, vol. 12, no. 2, pp. 121-134, 2001.

[12] C. A. O'Reilly and J. A. Chatman, "Culture as social control: Corporations, cults, and commitment," Research in organizational behavior: An annual series of analytical essays and critical reviews, vol. 18, 1996.

[13] D. E. Leidner and T. Kayworth, "A review of culture in information systems research: Toward a theory of information technology culture conflict," MIS Quarterly, vol. 30, no. 2, pp. 357-399, 2006.

[14] M. Sakurai and Ø. Sæbø, "Online Activities to Mobilize Smart Cities," in Hawaii International Conference on System Sciences 2018, Hilton Waikoloa Village, Hawaii, 2018.

[15] H. Chourabi et al., "Understanding smart cities: An integrative framework," in 45th Hawaii international conference on system sciences, 2012, pp. 2289-2297.

[16] C. F. Breidbach and P. P. Maglio, "Technology-enabled value co-creation: An empirical analysis of actors, resources, and practices," Industrial Marketing Management, vol. 56, pp. 73-85, 2016/07/01/ 2016.

[17] A.-v. Anttiroiko, "City-as-a-platform: Towards citizencentre platform governance," in RSA Winter Conference, 2016.

[18] E. Almirall, M. Lee, and A. Majchrzak, "Open innovation requires integrated competition-community ecosystems: Lessons learned from civic open innovation," Business horizons, vol. 57, no. 3, pp. 391-400, 2014.

[19] M. Gascó, "What makes a city smart? Lessons from Barcelona," in 49th Hawaii International Conference on System Sciences (HICSS), 2016, pp. 2983-2989.

[20] N. Komninos, Intelligent cities: innovation, knowledge systems and digital spaces. Routledge, 2013.

[21] A. Coe, G. Paquet, and J. Roy, "E-Governance and Smart Communities:A Social Learning Challenge," Social Science Computer Review, vol. 19, no. 1, pp. 80-93, 2001.

[22] K. Hampton and B. Wellman, "Neighboring in Netville: How the Internet Supports Community and Social Capital in a Wired Suburb," City \& Community, vol. 2, no. 4, pp. 277$311,2003$.

[23] K. N. Hampton, "Neighborhoods in the Network Society the e-Neighbors study," Information, Communication \& Society, vol. 10, no. 5, pp. 714-748, 2007.

[24] M. Ilena, H. Ard, and B. Wim, "On the development of online cities and neighborhoods: An exploration of cummulative and segmentive network effects in social media," presented at the European Conference on Information Systems (ECIS), Barcelona, Spain, 2011.

[25] T. Böhmann, J. Leimeister, and K. Möslein, "Service Systems Engineering," Bus Inf Syst Eng, vol. 6, no. 2, pp. 7379, 2014/04/01 2014.

[26] S. L. Vargo and R. F. Lusch, "Evolving to a new dominant logic for marketing," Journal of Marketing, vol. 68 , no. 1, pp. 1-17, 2004.

[27] K. Storbacka, R. J. Brodie, T. Böhmann, P. P. Maglio, and S. Nenonen, "Actor engagement as a microfoundation for value co-creation," Journal of Business Research, vol. 69, no. 8, pp. 3008-3017, 2016.

[28] C. F. Breidbach and R. J. Brodie, "Engagement platforms in the sharing economy: conceptual foundations and research directions," Journal of Service Theory and Practice, vol. 27, no. 4, 2017.

[29] C. Legner et al., "Digitalization: opportunity and challenge for the business and information systems engineering community," Bus Inf Syst Eng, vol. 59, no. 4, pp. 301-308, 2017.

[30] S. L. Vargo and M. A. Akaka, "Value cocreation and service systems (re)formation: A service ecosystems view," Service Science, vol. 4, no. 3, pp. 207-217, 2012.

[31] K. C. Desouza and T. H. Flanery, "Designing, planning, and managing resilient cities: A conceptual framework," Cities, vol. 35, pp. 89-99, 2013.

[32] R. Khatoun and S. Zeadally, "Smart cities: concepts, architectures, research opportunities," Commun. Acm, vol. 59, no. 8, pp. 46-57, 2016.

[33] A. L. Ostrom, A. Parasuraman, D. E. Bowen, L. Patricio, C. A. Voss, and K. Lemon, "Service research priorities in a rapidly changing context," Journal of Service Research, vol. 18, no. 2, pp. 127-159, 2015.

[34] C. Grotherr, M. Semmann, and T. Böhmann, "Using Microfoundations of Value Co-Creation to Guide Service Systems Design - A Multilevel Design Framework," presented at the International Conference on Information Systems (ICIS), San Francisco, California, USA, 2018.

[35] J. Barney and T. Felin, "What are microfoundations?," The Academy of Management Perspectives, vol. 27, no. 2, pp. 138-155, 2013. 
[36] R. F. Lusch and S. L. Vargo, Service-dominant logic: Premises, perspectives, possibilities. Cambridge University Press, 2014.

[37] P. Hedström and R. Swedberg, "Social mechanisms: An introductory essay," in Social mechanisms: An analytical approach to social theory, P. Hedström and R. Swedberg, Eds. Cambridge, UK: Cambridge University, 1998, pp. 1-31.

[38] J. Pannafino and P. McNeil, UX Methods: A Quick Guide to User Experience Research Methods. 2017.

[39] R. O. Briggs, T. Böhmann, G. Schwabe, and T. Tuunanen, "Advancing Design Science Research with Solution-based Probing," in 52nd Hawaii International Conference on System Sciences (HICSS), 2019: University of Hawai'i at Manoa.

[40] R. K. Yin, Case study research and applications: Design and methods. Sage publications, 2017.

[41] W. J. Mitchell, Placing words: Symbols, space, and the city. MIT press, 2005.

[42] G. Schwabe and H. Krcmar, "Piloting Socio-Technical Innovation," in European Conference on Information Systems (ECIS), Vienna, Austria, 2000, p. 27.

[43] P. Vogel, N. Jurcevic, and C. Meyer-Blankart, "Healthy, Active and Connected: Towards Designing an Age-Friendly Digital Neighborhood Platform," in European Conference on Information Systems (ECIS), Stockholm, Sweden, 2019.

[44] D. Gooch, A. Wolff, G. Kortuem, and R. Brown, "Reimagining the role of citizens in smart city projects," in Adjunct Proceedings of the 2015 ACM International Joint Conference on Pervasive and Ubiquitous Computing and Proceedings of the 2015 ACM International Symposium on Wearable Computers, 2015: ACM, pp. 1587-1594.

[45] D. Schlagwein, K. Conboy, J. Feller, J. M. Leimeister, and L. Morgan, "'Openness" with and without Information Technology: a framework and a brief history," Journal of Information Technology, vol. 32, no. 4, pp. 297-305, 2017.

[46] T. Buffel, C. Phillipson, and T. Scharf, "Experiences of neighbourhood exclusion and inclusion among older people living in deprived inner-city areas in Belgium and England," Ageing and Society, vol. 33, no. 1, pp. 89-109, 2013.

[47] A. K. Leist, "Social Media Use of Older Adults: A MiniReview," Gerontology, vol. 59, no. 4, pp. 378-384, 2013.

[48] F. Boll, P. Brune, and H. Gewald, "Towards Your Parents' Social Network Platform - A User Interface For the Age of Retirement," presented at the 50th Hawaii International Conference on System Sciences (HICSS), Waikaloa Village, HI, USA, 2017.

[49] S. Goswami, F. Köbler, J. M. Leimeister, and H. Krcmar, "Using Online Social Networking to Enhance Social Connectedness and Social Support for the Elderly," presented at the International Conference on Information Systems (ICIS), St. Louis, United States, 2010.

[50] C. Breidbach, R. Brodie, and L. Hollebeek, "Beyond virtuality: from engagement platforms to engagement ecosystems," Managing Service Quality, vol. 24, no. 6, pp. 592-611, 2014.

[51] M. Sein, O. Henfridsson, S. Purao, M. Rossi, and R. Lindgren, "Action design research," MIS Quarterly, vol. 35, no. 1, pp. 37-56, 2011.

[52] M. Semmann and C. Grotherr, "How to Empower Users for Co-Creation - Conceptualizing an Engagement Platform for Benefits Realization," presented at the 13th International Conference on Wirtschaftsinformatik, St. Gallen, Switzerland, 2017.

[53] T. Brown, Change by Design: How Design Thinking Transforms Organizations and Inspires Innovation. HarperCollins, 2009.

[54] J. M. Leimeister, U. Bretschneider, M. Huber, and H. Krcmar, "Leveraging Crowdsourcing: Activation-Supporting Components for IT-Based Ideas Competition," Journal of Management Information Systems, vol. 26, no. 1, pp. 197224, 2009.

[55] J. Venable, J. Pries-Heje, and R. Baskerville, "FEDS: a Framework for Evaluation in Design Science Research," European Journal of Information Systems, journal article vol. 25, no. 1, pp. 77-89, 2016.

[56] B. Gaver, T. Dunne, and E. Pacenti, "Design: Cultural Probes," Interactions, vol. 6, no. 1, pp. 21-29, 1999.

[57] G. Goldkuhl, "The IT artefact: An ensemble of the social and the technical?-A rejoinder: An ensemble of the social and the technical?-A rejoinder," Systems, Signs \& Actions, vol. 7, no. 1, pp. 90-99, 2013.

[58] R. Haines, J. Hough, L. Cao, and D. Haines, "Anonymity in computer-mediated communication: More contrarian ideas with less influence," Group Decision and Negotiation, vol. 23, no. 4, pp. 765-786, 2014.

[59] S. Mersand, M. Gasco-Hernandez, E. Udoh, and J. R. Gil-Garcia, "Public libraries as anchor institutions in smart communities: Current practices and future development," in 52nd Hawaii International Conference on System Sciences (HICSS), 2019.

[60] J. L. Wiles, A. Leibing, N. Guberman, J. Reeve, and R. E. S. Allen, "The Meaning of "Aging in Place" to Older People," The Gerontologist, vol. 52, no. 3, pp. 357-366, 2012.

[61] P. Echeverri and P. Skålén, "Co-creation and codestruction: A practice-theory based study of interactive value formation," Marketing Theory, vol. 11, no. 3, pp. 351373,2011

[62] M. Cassitas Hino and M. A. Cunha, "Study of Individual Differences in the Behavior of Mobile Technology Users in the Context of Urban Mobility," in 52nd Hawaii International Conference on System Sciences (HICSS), 2019. [63] A. Caragliu, C. Del Bo, and P. Nijkamp, "Smart cities in Europe," Journal of urban technology, vol. 18, no. 2, pp. 6582, 2011

[64] M. Ball and P. J. Maginn, "Urban change and conflict: Evaluating the role of partnerships in urban regeneration in the UK," Housing Studies, vol. 20, no. 1, pp. 9-28, 2005.

[65] T. Felin, N. J. Foss, and R. E. Ployhart, "The microfoundations movement in strategy and organization theory," Academy of Management Annals, vol. 9, no. 1, pp. 575-632, 2015.

[66] F. Bélanger, M. Cefaratti, T. Carte, and S. E. Markham, "Multilevel research in information systems: Concepts, strategies, problems, and pitfalls," Journal of the Association for Information Systems, vol. 15, no. 9, 2014.

[67] R. F. Lusch and S. Nambisan, "Service Innovation: A Service-Dominant Logic Perspective," MIS Quarterly, vol. 39, no. 1, pp. 155-175, 2015. 